\title{
Evaluation of isosorbide mononitrate for cervical ripening prior to induction of labor at term pregnancy in an outpatient setting
}

\author{
Neelam Meena $^{1}$, Neeta Bindal ${ }^{1}$, Shivraj Meena ${ }^{2}$ \\ ${ }^{1}$ Department of Obstetrics \& Gynaecology, DDU Hospital, Harinagar, New Delhi-64, India \\ ${ }^{2}$ Department of Obstetrics \& Gynaecology, Government Medical College, Kota, Rajasthan, India
}

Received: 16 January 2016

Accepted: 15 February 2016

\section{*Correspondence:}

Dr. Neelam Meena,

E-mail:dr.neeluck@gmail.com

Copyright: (C) the author(s), publisher and licensee Medip Academy. This is an open-access article distributed under the terms of the Creative Commons Attribution Non-Commercial License, which permits unrestricted non-commercial use, distribution, and reproduction in any medium, provided the original work is properly cited.

\begin{abstract}
Background: The objectives of the study were to Evaluation of isosorbide mononitrate for cervical ripening prior to induction of labor at term pregnancy in an outpatient.

Methods: A randomized, placebo controlled prospective study was conducted with 120 women with term pregnancies and unfavorable cervices who self-administered vaginally either 2, 40-mg tablets of IMN or pyridoxine as placebo prior to admission for induction of labor. The main outcome variables were change in Bishop Score, time from admission to delivery, and presence or absence of fetal and maternal morbidity.

Results: The Bishop score was significantly improved 24 hours after initiation of the outpatient IMN treatment. In study group change in Bishops score was $4.83 \pm 1.88$ and in control group was $1.07 \pm 1.27$. The needs for further cervical ripening and oxytocin infusion were less in the study than in the control group $(\mathrm{P}=0.001)$. The time from admission to delivery was also less $(\mathrm{P} \leq 0.001)$. Moreover, the IMN treatment had no major adverse maternal or fetal effects. The vast majority of women in both groups were either satisfied or very satisfied with the outpatient treatment.

Conclusions: IMN self-administered at home is safe and effective for cervical ripening prior to induction of labor in women with term pregnancies. It is the very effective method for cervical ripening in outpatient setup.
\end{abstract}

Keywords: Cervical ripening, Induction of labour, Isosorbide mononitrate, Outpatient setting, Term pregnancy

\section{INTRODUCTION}

Now a day Cervical status is a most accepted predictor of successful induction of labor and main cause of induction failure is unripe cervix. ${ }^{1,2}$ But at this time best method for cervical ripening has not been agreed by practitioner. Outpatient cervical ripening is associated with significantly shorter admission to delivery times and/or reduced health care costs. ${ }^{3-5}$ Hence there is increasing interest in carrying out cervical ripening on an outpatient basis. The use of prostaglandins for outpatient cervical ripening has been declared unsafe by many authorities because of their potential for uterine contractions to cause fetal hypoxia which would remain undiagnosed in the outpatient environment. ${ }^{6,7}$

An agent that ripens the cervix without stimulating uterine activity would be ideal for outpatient treatment. Nitric oxide (NO) is a free radical which has been studied for cervical ripening. ${ }^{8}$ The main effect of $\mathrm{NO}$ is rearrangement of collagen, thereby allowing NO to soften the cervix without causing uterine contractions. ${ }^{9}$ It has also been seen that a reduction of NO in the cervix may be a cause of post-term pregnancy. ${ }^{10}$

In contrast to prostaglandins, nitric oxide donors inhibit rather stimulate uterine contractions, and promote rather 
than restrict uterine blood flow. Thus nitric oxide donors such as IMN appear to be the ideal cervical ripening agent prior to labour induction. ${ }^{11}$ Isosorbide mono nitrate (IMN) is a nitric oxide (NO) donor that can be used for cervical ripening without causing uterine contractions and the need for fetal monitoring and therefore be safely administered at home. , $^{8}$

Studies have also shown that vaginal IMN has no clinically significant adverse effects on either maternal or fetal haemodynamics. ${ }^{13}$ There are very few studies that have evaluated the role of NO donors for cervical ripening. We therefore carried out a study to evaluate the efficacy and safety of isosorbide mononitrate for cervical ripening prior to induction of labor at term pregnancy in an outpatient setting in India.

\section{METHODS}

A randomized, placebo-controlled prospective study was conducted in the Department of Obstetrics and Gynaecology, Deen Dayal Upadhyay Hospital, New Delhi from January 2014 to November 2014.This study conducted in 120 pregnant women who come to the DDU hospital, presenting with term pregnancy with cephalic presentation and non-high risk group. Total participants are divided in two groups (60 in intervention and 60 in control).

A written informed consent was taken from each woman included in the study after thorough counselling. All cases were selected, taking into consideration the inclusion \& exclusion criteria. Inclusion criteria were pregnancy more than $40 \mathrm{wks}$ of gestation, live singleton fetus, Cephalic presentation, intact membrane, Bishop Score $\leq 6$, not in labor and Parity of 3 or less. Exclusion criteria were Previous caesarean delivery, Malpresentation, Placenta previa, Severe intrauterine growth restriction, multiple pregnancies, polyhydramnios, oligohydramnios, Bishop score $\geq 7$, medical diseases in pregnancy (PIH, BA, heart disease, DM etc.) and drugs allergy. A detailed history and complete general and obstetrics examination was done for patient recruited in the study. Baseline Bishop Score were recorded on per vaginal examination. Obstetric ultrasound was done for fetal wellbeing. The patients were given either 2 doses $40-\mathrm{mg}$ tablets of IMN or 2 doses 40-mg tablets of pyridoxine as placebo randomly.1st dose of one of the tablets was put vaginally in hospital by doctor and patient was kept for observation for 1 hour. They were asking to report to hospital immediately if experienced labor pains, vaginal leaking or bleeding, or a decrease in fetal movements. If they had no complained than patient was instructed to selfadminister 2nd dose of tab at home vaginally after 12 hour and report to the hospital 12 hour later for admission.

The Bishop score were recorded again on admission .If bishop score is favourable $>6$ than labor is augment with low-dose oxytocin infusion and in unfavourable, a 0.5 mg $\mathrm{PGE}_{2}$ gel (Cerviprime; in hospital supply) is instilled intracervically then manage according to progress of labour. All record was maintained.

The primary outcome that were evaluated change in Bishop Score before drug administration and on admission and time interval from induction to delivery, whether vaginally or caesarean. Other maternal outcome variables were presence or absence of tachycardia, hypotension, headache, and palpitations. The fetal outcome variables are Apgar scores at 1 and 5 minutes and whether admission to the neonatal nursery is necessary. Secondary outcomes were the need for inpatient cervical ripening treatment, a subsequent need for oxytocin, operative delivery rates, and complications such as uterine hyper stimulation, tachysystole, meconium-stained liquor, and postpartum haemorrhage. Patient satisfaction to outpatient treatment by likert scale.

Statistical analysis was performed with the statistical package for the social science system version SPSS 17. Continuous variables are presented as mean $\pm \mathrm{SD}$, and categorical variables are presented as absolute numbers and percentage. The comparison of normally distributed continuous variables between the groups was performed using Student's t test. Nominal categorical data between the groups were compared using Chi-squared test or Fisher's exact test as appropriate. $\mathrm{P}<0.05$ was considered statistically significant.

\section{RESULTS}

A total of 280 patients were screened in which 120 patients were eligible and randomized. 60 to the study and 60 to the control group. Their characteristics were similar in the two groups (Table 1).

Comparisons of the studied labor and delivery variables between the groups are shown in Table 2. Mean baseline bishops score in study group and control group was $1.42 \pm 0.62$ and $1.31 \pm 0.60$ respectively $(\mathrm{P}=0.345)$. Significant difference occurred in Bishops score after drug administration. In study group and control group mean bishop score on admission was $6.25 \pm 2.04 \mathrm{v} / \mathrm{s}$ $2.34 \pm 1.56$ and change in bishop score was $4.83 \pm 1.88 \mathrm{v} / \mathrm{s}$ $1.07 \pm 1.27$ respectively $(\mathrm{P}=<0.001)$. Percentage of Bishop Score $<6$ and PGE2, Bishop Score $<6$ and PGE2 with oxytocin and augment by oxytocin in study were $6.7 \%$, $35.0 \%, 58.3 \%(\mathrm{P}=0.001)$. The needs of further cervical ripening with PGE2 and PGE2 with oxytocin were low in study group compare to control. More patient come in active labor in study group which were required only oxytocin for augmentation. After the outpatient IMN treatment $21.7 \%$ and $36.2 \%$ of the participants in the study and control groups underwent a caesarean delivery, but the difference was not significant. The most common indication for a caesarean delivery in the study (13.3\%) and in the control (17.2\%) group was a failed induction. The differences in percentages of participants for the 
other indications were also not significant. The time taken admission to delivery was (mean \pm SD) $467.33 \pm 214.79 \mathrm{~min}$. and in control group it was $711.31 \pm 275.84 \mathrm{~min}$. Duration of admission to delivery was significantly shorter in study group $(\mathrm{P} \leq 0.001)$.

Table 1: Demographic characteristics of the study participants.

\begin{tabular}{|llll|} 
Characteristic & $\begin{array}{l}\text { Study } \\
\text { group } \\
\text { N=60 }\end{array}$ & $\begin{array}{l}\text { Control } \\
\text { group } \\
\text { N=58 }\end{array}$ & P value \\
\hline Age(years) & $\begin{array}{l}23.93 \pm \\
2.64\end{array}$ & $\begin{array}{l}23.14 \pm \\
2.73\end{array}$ & 0.110 \\
\hline $\begin{array}{l}\text { Gestational age } \\
\text { (weeks) }\end{array}$ & $40.17 \pm$ & $40.29 \pm$ & \multirow{2}{*}{0.105} \\
\hline Parity & 0.376 & 0.459 & \\
Nulliparous & $68 \%$ & $71 \%$ & 0.781 \\
Multiparous & $32 \%$ & $29 \%$ & \\
\hline Educational status & & & \\
Illiterate & $8.30 \%$ & $17.2 \%$ & \\
Primary & $31.7 \%$ & $32.8 \%$ & \\
High School & $48.3 \%$ & $37.9 \%$ & 0.458 \\
Graduation & $11.7 \%$ & $12.1 \%$ & \\
\hline Booking status & & & \\
Booked & $78.3 \%$ & $74.1 \%$ & 0.592 \\
Unbooked & $21.7 \%$ & $25.9 \%$ & \\
\hline
\end{tabular}

Values are given as mean \pm SD or percentage unless otherwise indicated.

Table 2: Between-groups comparison of labor and delivery variables.

\begin{tabular}{|c|c|c|c|}
\hline variable & $\begin{array}{l}\text { Study } \\
\text { group } \\
\mathbf{N}=60\end{array}$ & $\begin{array}{l}\text { Control } \\
\text { group } \\
\mathbf{N}=\mathbf{5 8}\end{array}$ & P value \\
\hline $\begin{array}{l}\text { Baseline } \\
\text { Bishops score }\end{array}$ & $\begin{array}{l}1.42 \pm \\
0.62\end{array}$ & $\begin{array}{l}1.31 \pm \\
0.60\end{array}$ & 0.345 \\
\hline $\begin{array}{l}\text { Bishops score } \\
\text { on admission } \\
\text { after drug }\end{array}$ & $\begin{array}{l}6.25 \pm \\
2.04\end{array}$ & $\begin{array}{l}2.34 \pm \\
1.56\end{array}$ & $<0.001$ \\
\hline $\begin{array}{l}\text { Change in } \\
\text { Bishops score }\end{array}$ & $\begin{array}{l}4.83 \pm \\
1.88\end{array}$ & $\begin{array}{l}1.07 \pm \\
1.27\end{array}$ & $<0.001$ \\
\hline $\begin{array}{l}\text { Bishop score } \\
<6 \text { and PGE2 }\end{array}$ & $6.7 \%$ & $20.7 \%$ & 0.032 \\
\hline $\begin{array}{l}\text { Bishop score } \\
<6 \text { and PGE2 } \\
\text { with oxytocin }\end{array}$ & $35.0 \%$ & $70.7 \%$ & $<0.001$ \\
\hline $\begin{array}{l}\text { Augment by } \\
\text { oxytocin }\end{array}$ & $58.3 \%$ & $8.6 \%$ & $<0.001$ \\
\hline $\begin{array}{l}\text { Caesarean } \\
\text { delivery }\end{array}$ & $21.7 \%$ & $36.2 \%$ & NA \\
\hline $\begin{array}{l}\text { Duration of } \\
\text { admission to } \\
\text { delivery (min) }\end{array}$ & $\begin{array}{l}467.33 \pm \\
214.79\end{array}$ & $\begin{array}{l}711.31 \pm \\
275.84\end{array}$ & $<0.001$ \\
\hline
\end{tabular}

Values are given as mean \pm SD or percentage unless otherwise indicated.
Table 3: Between-groups comparison of adverse maternal effects.

\begin{tabular}{|c|c|c|c|}
\hline Adverse effect & $\begin{array}{l}\text { Study } \\
\text { group } \\
\mathbf{N}=60\end{array}$ & $\begin{array}{l}\text { Control } \\
\text { group } \\
\mathbf{N}=58\end{array}$ & $P$ value \\
\hline \multicolumn{4}{|l|}{ Headache } \\
\hline $\begin{array}{l}\text { Not requiring } \\
\text { medication }\end{array}$ & $25.0 \%$ & $3.4 \%$ & 0.001 \\
\hline $\begin{array}{l}\text { Requiring } \\
\text { medication }\end{array}$ & $3.3 \%$ & $0.0 \%$ & 0.496 \\
\hline Palpitation & $1.7 \%$ & $0.0 \%$ & 1.000 \\
\hline Tachycardia & $0.0 \%$ & $0.0 \%$ & NA \\
\hline Hypotension & $0.0 \%$ & $0.0 \%$ & NA \\
\hline \multicolumn{4}{|l|}{ labor complications } \\
\hline Tachysystole & $0.0 \%$ & $5.2 \%$ & 0.112 \\
\hline $\begin{array}{l}\text { Post-partum } \\
\text { haemorrhage }\end{array}$ & $0.0 \%$ & $1.7 \%$ & 0.492 \\
\hline Fetal distress & $1.7 \%$ & $8.6 \%$ & 0.111 \\
\hline $\begin{array}{l}\text { Meconium Stained } \\
\text { Liquor }\end{array}$ & $13.3 \%$ & $29.3 \%$ & 0.028 \\
\hline
\end{tabular}

Values are given as mean \pm SD or percentage unless otherwise indicated.

No major adverse effects of IMN were observed and no one in the study group avoided using the second dose. The main adverse effects experienced in the study group were headache $(28.3 \%)$ and palpitations $(1.7 \%)$. Other side effect like hypotension and tachycardia were not occurred in both groups. In the study group labor complication was $1.67 \%$ fetal distress and $13.3 \%$ meconium stained liquor. There was no complication such as PPH and tachysystole in study group. But in control group $3(5.2 \%)$ tachysystole, 1 (1.7\%) postpartum haemorrhage, $5(8.6 \%)$ fetal distress and 17 (29.3\%) meconium stained liquor were occurred (Table $3)$.

Table 4: Between-groups comparison of neonatal outcomes.

\begin{tabular}{|lll|l|}
\hline outcome & $\begin{array}{l}\text { Study } \\
\text { group } \\
\text { N=60 }\end{array}$ & $\begin{array}{l}\text { Control } \\
\text { group } \\
\mathbf{N}=58\end{array}$ & P value \\
\hline $\begin{array}{l}\text { Apgar } \\
\text { score }<7 \text { in 1 } \\
\text { min }\end{array}$ & $3.3 \%$ & $22.2 \%$ & 0.002 \\
\hline $\begin{array}{l}\text { Apgar } \\
\text { score }<7 \text { at 5 } \\
\text { min }\end{array}$ & $0.0 \%$ & $1.7 \%$ & 1.000 \\
\hline $\begin{array}{l}\text { Admission } \\
\text { in nursery }\end{array}$ & $0.0 \%$ & $5.2 \%$ & 0.116 \\
\hline
\end{tabular}

Values are given as mean $\pm \mathrm{SD}$ or percentage unless otherwise indicated.

In study group $2(3.3 \%)$ babies and in control group 13 $(22.4 \%)$ had $<7$ Apgar score at 1 mint.In study group no babies had $<7$ Apgar score at $5 \mathrm{~min}$ and admission to nursery but in control group 1(1.7\%) baby had <7 Apgar 
score at $5 \mathrm{~min}$ and 3 babies were admitted in nursery (Table 4).

\section{DISCUSSION}

Cervical ripening is main component of labor which required many hours. The change in Bishop score and, compared with the control group, the lesser need for prostaglandin and oxytocin administration, the lesser need for caesarean delivery, and the shorter time from admission to delivery attest to the effectiveness of IMN treatment for cervical ripening.

In present study, mean of change in bishop score in study and control group was $4.83 \pm 1.88 \mathrm{v} / \mathrm{s} \quad 1.07 \pm 1.27$ respectively ( $\mathrm{P} \leq 0.001)$. In the study by Bollapragada et al the mean change in Bishop score after IMN administration was 0.65 but it was greater in Osman et al and Agarwal K et al, $(3.17 \pm 2.02$ v/s $0.25 \pm 0.93, \mathrm{P} \leq 0.001)$ this could be because Bollapragada et al was used single dose of IMN and recruited only nulliparous women whereas other studies, as well as the present study, included both nulliparous and parous women. ${ }^{14-16}$ In Helal et al change in bishop after IMN was $6.5 \pm 2$ and in control $2 \pm 1.1$. All studies showing that mean of change in bishop score were more in IMN group. ${ }^{17}$

In our study further need for inpatient cervical ripening with PGE2 was $(46.6 \%$ v/s $88.3 \%)$ which was statistically significant ( $\leq \leq 0.001$ ). Bollapragada et al, Agarwal K et al and Bullarbo et al also found that the percentages of women requiring prostaglandins after IMN treatment were lower in their IMN groups than in their control groups. ${ }^{14,16,18}$ Same result were obtain from sheriff et al $(\mathrm{P}=0.002)$ and in Eddama et al result were not significant $(\mathrm{P}=0.065) .{ }^{19,20}$

The caesarean delivery rate was lower in the study group than in the control group (21.7\% v/s 36.2\%), although the difference was not significant $(\mathrm{P}=0.081)$. Similar rates were reported by Agarwal et al (22\% v/s 31\%), Eddama et al $(37 \% \mathrm{v} / \mathrm{s} 33 \%)$, and Helal et al $(7.5 \% \mathrm{v} / \mathrm{s}$ $2.5 \%) .^{16,17,20}$ Rate of caesarean section in both group of all studies were not significant which same as our study.

In present study the mean time from admission to delivery was less in the study group $(467.33 \pm 214.79 \mathrm{v} / \mathrm{s}$ $711.31 \pm 2.75 .84$ minutes $)(\mathrm{P}=0.001)$. This result was similar in Agarwal $\mathrm{K}$ et al in which mean time from admission to delivery was $(9.7 \pm 5.28 \mathrm{v} / \mathrm{s} \quad 13.49 \pm 4.35$ hours) $(\mathrm{P} \leq 0.001)$ and in Eddama et al $(25.06 \mathrm{v} / \mathrm{s} 26.66$ hours) $(\mathrm{P}=0.37){ }^{16,20}$ In Eddama et al, there was no significant difference, because all patients which selected were nulliparous and this study conducted mainly for cost effectiveness of drug. ${ }^{20}$ Hamideh et al (33.9 v/s 36.2 hours) and in Bollapragada et al results were Different explained by the differences in parity of patients, mean gestational age at delivery and the indication for the induction of labour. ${ }^{14,21}$ In our study no major side effect associated with IMN but some patients had complain of mild headache $28.3 \%$ v/s $3.4 \%(\mathrm{P}=0.496)$ in which 2 patient required medication in study group but no one in control group. It was not significant. Only one patient had complained of palpitation. In Agarwal K et al study, 63\% patients had mild headache in IMN group and $10 \%$ were required medication and in Helal et al most common side effect associated with IMN was Headache $70 \%$ in study group comparison with 2 only in control. ${ }^{16,17}$

The present study confirms previous reports that vaginally administered IMN induces neither uterine hyper stimulation nor tachysystole [Osman I et al, Agarwal K et al]. ${ }^{15,16}$ Post-partum haemorrhage was not reported in present study but 2 cases of PPH were reported in Agarwal K et al. ${ }^{16}$

In present study, occurrence of FD and MSL in study and control group were $1.67 \% \mathrm{v} / \mathrm{s} 13.3 \%$ and $8.6 \% \mathrm{v} / \mathrm{s} 29.3 \%$ respectively whereas in Agarwal K et al showed 19\% v/s $16 \%$ and $32 \% \mathrm{v} / \mathrm{s} 21 \%$ respectively. ${ }^{16}$ This finding is in agreement with previous studies where no abnormal fetal heart tracings were identified after IMN treatment in women with pregnancies at term (Osman $\mathrm{I}$ et al, Bollapragada et al). ${ }^{14,17}$

In this study Apgar score $<7$ at $1 \mathrm{~min}$ and $<7$ at 5 min was $3.3 \%$ and $0.0 \%$ respectively in study group. The Apgar score was not affected by the use of IMN. Other studies also found that the incidence of Apgar scores less than 7 at 5 minutes was only $1.7 \%$ or $2 \%$ in their IMN groups (Bollapragada et al, Bullarbo $\mathrm{M}$ et al). ${ }^{14,18}$

\section{CONCLUSIONS}

IMN self-administered at home is safe and effective method for cervical ripening prior to induction of labor in women with term pregnancies as well as in outpatient setup.

\section{Funding: No funding sources \\ Conflict of interest: None declared \\ Ethical approval: The study was approved by the Institutional Ethics Committee}

\section{REFERENCES}

1 Abdellah MS, Hussein M, Aboalhassan A. Intravaginal administration of isosorbide mononitrate and misoprostol for cervical ripening and induction of labor: A randomized controlled trial. Arch Gynecol Obstet. 2011;284:25-30.

2 Watson WJ, Stevens D, Welter S, Day D. Factors predicting successful labour induction. Obstet Gynecol. 1996;88:990-2.

3 Stitely ML, Browning J, Fowler M, Gendron RT, Gherman RB. Outpatient cervical ripening with intravaginal misoprostol. Obstet Gynecol. 2000;96(5Pt 1):684-8. 
4 McKenna DS, Costa SW, Samuels P: Prostaglandin E2 cervical ripening without subsequent induction of labor. Obstet Gynecol. 1999;94(1):11-4.

5 Farmer KC, Schwartz WJ 3rd, Rayburn WF, Turnbull G. A cost minimization analysis of intracervical prostaglandin E2 for cervical ripening in an outpatient versus inpatient setting. Clin Ther. 1996;18(4):747-56.

6 Rayburn W, Tassone S, Pearman C: Is cervidil appropriate for outpatient cervical ripening. Obstet Gynecol. 2000;95:S63.

7 Voss DH, Cumminsky KC, Cook VD, Nethers MS, Spinnato JA, Gall SA: Effect of three concentrations of intracervical prostaglandin E2 gel for cervical ripening. J Matern Fetal Med. 1996;5(4):186-93.

8 Chwalisz K, Garfield RE. Nitric oxide as the final metabolic mediator of cervical ripening. Hum Reprod. 1998;13:245-8.

9 Ledingham MA, Denison FC, Kelly RW, Young A, Norman JE. Nitric oxide donors stimulate prostaglandin F (2 alpha) and inhibit thromboxane B (2) production in the human cervix during the first trimester of pregnancy. Mol Hum Reprod. 1999;5:973-82.

10 Väisänen-Tommiska M. Nitric Oxide in Human Uterine Cervix: Role in Cervical Ripening. Academic Dissertation, Department of Obstetrics and Gynecology, Faculty of Medicine, Institute of Clinical Medicine, University of Helsinki. Finland. 2006:19-23.

11 Ekerhovd E, Bullarbo M, Andersch B, Norström A. Vaginal administration of the nitric oxide donor isosorbide mononitrate for cervical ripening at term: A randomized controlled study. Am J Obstet Gynecol. 2003;189:1692-7.

12 Ledingham MA, Thomson AJ, Greer IA, Norman JE. Nitric oxide in parturition. BJOG. 2000;7:581-93.

13 Nicoll AE, Machenzie F, Greer IA, Norman JE. Vaginal application of the nitric oxide donor isosorbide mononitrate for preinduction cervical ripening: A randomized controlled trial to determine effects on maternal and fetal hemodynamics. Am J Obstet Gynecol. 2001;184:958-64.

14 Bollapragada SS, MacKenzie F, Norrie JD, Eddama O. Randomised placebo-controlled trial of outpatient (at home) cervical ripening with isosorbide mononitrate (IMN) prior to induction of labour-clinical trial with analyses of efficacy and acceptability. The IMOP study. BJOG. 2009;116(9):1185-95.

15 Osman I, MacKenzie F, Norrie J, Murray HM. The "PRIM" study: a randomized comparison of prostaglandin E2 gel with the nitric oxide donor isosorbide mononitrate for cervical ripening before the induction of labor at term. Am J Obstet Gynecol. 2006;194(4):1012-21.

16 Agarwal K, Batra A, Batra A, Dabral A, Aggarwal A.Evaluation of isosorbide mononitrate for cervical ripening prior to induction of labor for postdated pregnancy in an outpatient setting. Int $\mathbf{J}$ Gynaecol Obstet. 2012;118(3):205-9.

17 Helal AMM, Abd El-Razek M. Randomized double -blind controlled study to determine the effect of vaginally applied nitric oxide donor (isosorbide mononitrate) for preinduction cervical ripening on maternal \& fetal hemodynamics and the ripening of the cervix. El-minia med. 2004;15(1).

18 Bullarbo M, Orrskog ME, Andersch B, Granström L, Norström A, Ekerhovd E. Outpatient vaginal administration of the nitric oxide donor isosorbide mononitrate for cervical ripening and labor induction post term: A randomized controlled study. Am J Obstet Gynecol. 2007;196:e1-5.

19 Habib SM, Emam SS, Saber AS. Outpatient cervical ripening with nitric oxide donor isosorbide mononitrate prior to induction of labor. Int $\mathrm{J}$ Gynaecol Obstet. 2008;101(1):57-61.

20 Eddama O, Petrou S, Schroeder L, Bollapragada SS, Mackenzie F, Norrie J. The cost-effectiveness of outpatient (at home) cervical ripening with isosorbide mononitrate prior to induction of labour. BJOG. 2009;116(9):1196-203.

21 Yazdizadeh H, Abedi P, Najar S. The impact of isosorbide mononitrate on cervical ripening and labor induction in primiparous women with term pregnancy: A double-blind, randomized, controlled trial. Iran J Nurs Midwifery Res. 2013;18(3):246-50.

Cite this article as: Meena N, Bindal N, Meena S. Evaluation of isosorbide mononitrate for cervical ripening prior to induction of labor at term pregnancy in an outpatient setting. Int J Reprod Contracept Obstet Gynecol 2016;5:793-7. 